\title{
Neurology Care, Diagnostics, and Emerging Therapies of the Patient With Duchenne Muscular Dystrophy
}

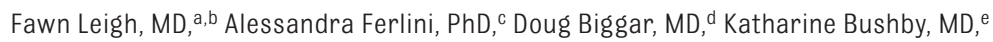

Richard Finkel, MD, ${ }^{f}$ Lauren P. Morgenroth, MS, ${ }^{8}$ Kathryn R. Wagner, MD, PhD ${ }^{\text {h,i }}$

Duchenne muscular dystrophy is the most common form of childhood muscular dystrophy. A mutation in the $D M D$ gene disrupts dystrophin (protein) production, causing damage to muscle integrity, weakness, loss of ambulation, and cardiopulmonary compromise by the second decade of life. Life expectancy has improved from mid-teenage years to mid20 s with the use of glucocorticoids and beyond the third decade with ventilator support and multidisciplinary care. However, Duchenne muscular dystrophy is associated with comorbidities and is a fatal disease. Glucocorticoids prolong ambulation, but their side effects are significant. Emerging investigational therapies have surfaced over the past decade and have rapidly been tested in clinical trials. Gene-specific strategies include nonsense readthrough, exon skipping, gene editing, utrophin modulation, and gene replacement. Other mechanisms include muscle regeneration, antioxidants, and antifibrosis and anti-inflammatory pathways. With potential therapies emerging, early diagnosis is needed to initiate treatment early enough to minimize morbidity and mortality. Newborn screening can be used to significantly improve early diagnosis, especially for gene-specific therapeutics.

Duchenne muscular dystrophy (DMD), although rare, is the most common muscular dystrophy, with a prevalence of 1 in $5000 .{ }^{1-3}$ It is an X-linked disorder caused by a mutation in the DMD gene located on Xp21. The DMD gene is large (79 exons; 427 Kilodalton) and encodes a 427-Kilodalton muscle isoform protein dystrophin. The gene is located in the dystrophin-associated glycoprotein complex at the sarcolemma and in the cytoskeleton. The protein is located primarily in skeletal muscle to stabilize the plasma membrane and maintain the strength of muscle fibers. ${ }^{4,5}$ The absence of dystrophin causes muscle membrane damage, elevated serum creatinine kinase (CK),

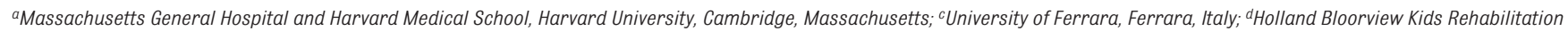
Hospital, Toronto, Ontario, Canada; ' John Walton Centre for Muscular Dystrophy Research, Institute of Genetic Medicine, Newcastle University, Newcastle upon Tyne, United Kingdom; ${ }^{f}$ Nemours Children's Health System, Orlando, Florida; ${ }^{g}$ Children's National Health System, Washington, District of Columbia; ${ }^{h}$ Kennedy Krieger Institute, Baltimore, Maryland; and 'School of Medicine, Johns Hopkins University, Baltimore, Maryland 'beattle Children's Hospital, University of Washington, Seattle, Washington

The guidelines or recommendations in this article are not American Academy of Pediatrics policy, and publication that was partially supported herein does not imply endorsement.

Dr Wagner served as the chairperson of the Duchenne Muscular Dystrophy Care Considerations Neuromuscular Management Working Group as convened by the Centers for Disease Control and Prevention and reviewed and revised the manuscript; Dr Leigh served in the Duchenne Muscular Dystrophy Care Considerations Neuromuscular Management Working Group as convened by the Centers for Disease Control and Prevention, drafted the initial manuscript, and reviewed and revised the manuscript; Drs Biggar, Bushby, and Finkel served in the Duchenne Muscular Dystrophy Care Considerations Neuromuscular Management Working Group as convened by the Centers for Disease Control and Prevention, contributed to the development of corresponding recommendations, and reviewed and revised the manuscript; Drs Ferlini and Morgenroth served in the Duchenne Muscular Dystrophy Care Considerations Diagnostics Management Working Group as convened by the Centers for Disease Control and Prevention, contributed to the development of corresponding recommendations, and reviewed and revised the manuscript; and all authors approved the final manuscript as submitted and agree to be accountable for all aspects of the work.

DOI: https://doi.org/10.1542/peds.2018-0333C 


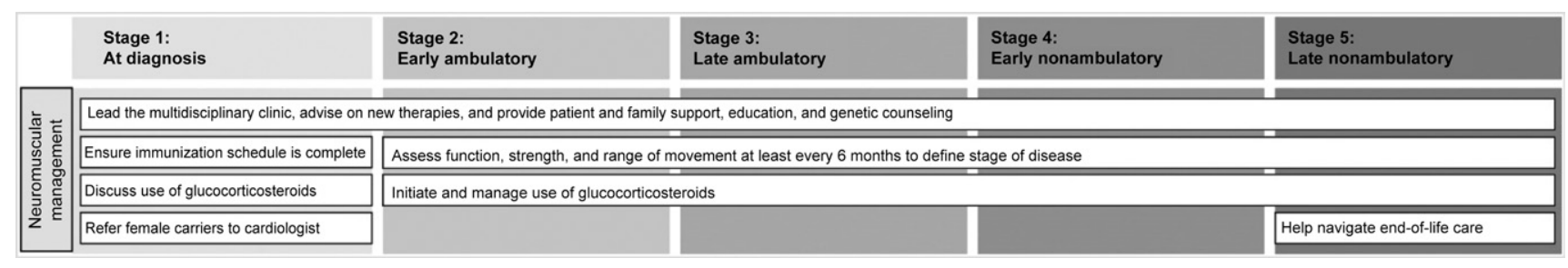

FIGURE 1

Summary of neuromuscular management depending on the clinical stage of patients with DMD. (Adapted with permission from Birnkrant DJ, Bushby $\mathrm{K}$, Bann CM, et al. Diagnosis and management of Duchenne muscular dystrophy, part 1: diagnosis, and neuromuscular, rehabilitation, endocrine, and gastrointestinal and nutritional management. Lancet Neurol. 2018;17(3):252.)

fiber necrosis, muscle degeneration, and regeneration. ${ }^{6}$ Constant muscle breakdown and necrosis is followed by inflammatory processes that lead to the replacement of muscle with fibrotic tissue and fat

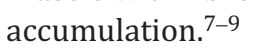

Common presenting symptoms include delayed motor milestones, inability to run or hop, toe walking, difficulty climbing stairs, and hypertrophy of calf muscles. Nonmotor presentations include failure to thrive, speech delay, fatigue, abnormal transaminases, myoglobinuria, and complications because of anesthesia (ie, malignant hyperthermia or rhabdomyolysis). Global developmental delay is a common presentation. Early signs and symptoms present at ages 2 to 3 years, whereas the average age of diagnosis is 3 to 5 years. It has been reported that it takes $>1$ year to confirm DMD from the time of presentation, ${ }^{10}$ which is far too long in a disease for which time means loss of muscle function and the familial risk of recurrence is up to $50 \%$ in male siblings.

With recent advancements in clinical trials, there is an unmet need to diagnose affected infants and children early. Mendell et al ${ }^{1}$ presented data on newborn screening in Ohio initiated with a CK level from dried blood spot followed by genetic confirmation of those with elevated CK. Eagle et al ${ }^{11}$ reported that life expectancy in the 1960s was 14 years; in the 1990s, life expectancy was 25 years for those receiving ventilatory support. The mean age at which patients lose ambulation is $\sim 9$ to 10 years..$^{11}$ Glucocorticoids are used to improve muscle strength and function in patients with DMD $^{12}$ and prolong ambulation ${ }^{13}$ by an additional 2 to 3 years ${ }^{14}$; patients with DMD who are treated with glucocorticoids become wheelchair dependent by 12 to 13 years of age. Loss of ambulation is associated with greater morbidity and mortality as the disease progresses; not surprisingly, the primary objective of researchers in most clinical trials is prolonging ambulation. Cardiomyopathy and respiratory insufficiency can shorten the life span, but with ventilator support, survival in DMD has been extended to $>30$ years, and cardiac function is the remaining determinant of survival. ${ }^{15}$ Investigational drugs that are used to improve cardiopulmonary function also have emerged in clinical trials (for additional details, see the specialty article on cardiac management that is part of this supplement ${ }^{16}$ ). Our purpose in this article is to guide clinicians in the diagnosis and treatment of DMD itself, expanding on principles outlined in the 2018 Duchenne Muscular Dystrophy Care Considerations sponsored by the Centers for Disease Control and Prevention. ${ }^{17}$ In Fig 1, we provide an overall guide for the neuromuscular management of patients with DMD according to each patient's clinical stage.

\section{NEUROLOGY}

DMD is a proximal myopathy affecting muscles, such as the quadriceps and gluteals. Fasttwitch (type IIb) myofibers are preferentially affected, leaving the slow-twitch (type I) type to predominate. ${ }^{18,19}$ The disease is characterized by muscle wasting, weakness, myofiber size variation with muscle necrosis, fat accumulation, connective tissue replacement, and paradoxical hypertrophy of calf muscles. Gait abnormality and difficulty getting up from a chair or from a supine position are common clinical features. However, the onset of symptoms can vary in age, severity, and presentation. Individuals affected by DMD typically present with delayed motor development or a gait abnormality, especially toe walking or delayed age of ambulation, and are often referred to physical therapy. Although the average age of presentation ranges from 2 to 5 years, the recognition of loss of milestone and the use of Bayley Scales of Infant Development, Third Edition can improve the identification of affected infants before motor impairment occurs. ${ }^{20-22}$

\section{GLUCOCORTICOIDS}

Prednisone prolongs ambulation and has been shown to have longterm benefits for respiratory and cardiac function in nonambulatory patients. ${ }^{12,13,23-25}$ Some researchers suggest there may be fewer side 
effects with deflazacort than prednisone. ${ }^{26,27}$ However, the relative efficacy and side effects of different glucocorticoid regimens remains untested in well-designed, head-to-head trials. The standard dose for prednisone is $0.75 \mathrm{mg} / \mathrm{kg}$ per day and for deflazacort is $0.9 \mathrm{mg} / \mathrm{kg}$ per day (Fig 2). For a more detailed discussion on glucocorticoid management, see the Supplemental Information.

\section{DIAGNOSIS}

Clinical variability, genetic heterogeneity, and the large size of the $D M D$ gene contribute to the complexity of diagnosis (Fig 3). Mutational analysis has made the confirmation of a molecular diagnosis possible in the majority of cases. However, diagnosis and prognosis are also dependent on clinical presentation and genetic profile. Genotype-phenotype correlation can help prognosticate, but age of presentation and family history are also important. For example, most exon deletions are correlated with disease severity on the basis of the "reading-frame rule" and apply to $\sim 92 \%$ of cases. ${ }^{28}$ The vast majority of whole-exon deletions or duplications are correlated with a pathogenic mutation. The reading-frame stop codon caused by an out-of-frame mutation disrupts the open reading frame and ablates the translation of dystrophin, causing a more severe $D M D$ phenotype. An in-frame mutation can still translate the open reading frame to a partial-length dystrophin, resulting in Becker muscular dystrophy and a milder phenotype. ${ }^{29}$ In some cases, in-frame mutations with worsening myopathy are more clinically consistent with DMD.

The methods used to diagnose DMD include clinical history, physical examination, serum $\mathrm{CK}$, liver enzymes, genetic testing, and perhaps muscle biopsy. In the past, muscle

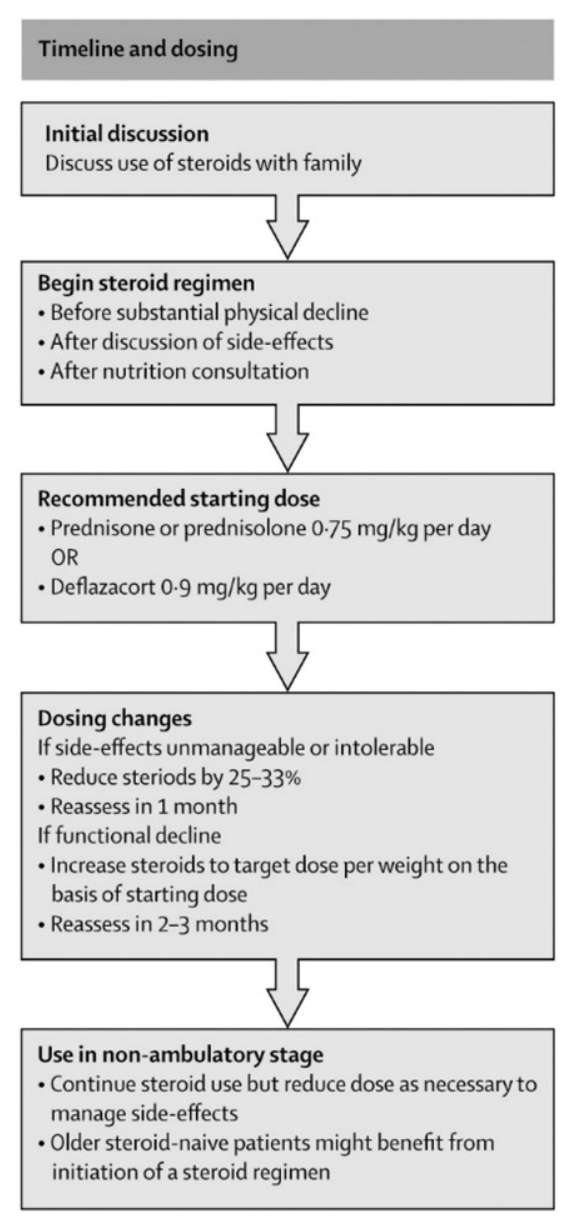

\section{Cautions}

Adrenal insufficiency

Patient and family education

- Educate on signs, symptoms, and management of adrenal crisis

Prescribe intramuscular hydrocortisone for

administration at home

- $50 \mathrm{mg}$ for children aged $<2$ years old

- $100 \mathrm{mg}$ for children aged $\geq 2$ years old and adults

Stress dosing for patients taking $>12 \mathrm{mg} / \mathrm{m}^{2}$ per day

of prednisone/deflazacort daily

- Might be required in the case of severe illness,

major trauma, or surgery

-Administer hydrocortisone at $50-100 \mathrm{mg} / \mathrm{m}^{2}$ per day

recommended starting dose

Prednisone or prednisolone $0.75 \mathrm{mg} / \mathrm{kg}$ per day

Deflazacort $0.9 \mathrm{mg} / \mathrm{kg}$ per day

\section{FIGURE 2}

Care considerations for glucocorticoid (steroid) initiation and use for patients with DMD. ACTH adrenocorticotropic hormone; CRH, corticotropin-releasing hormone; HPA, hypothalamic-pituitaryadrenal. (Reproduced with permission from Birnkrant DJ, Bushby K, Bann CM, et al. Diagnosis and management of Duchenne muscular dystrophy, part 1: diagnosis, and neuromuscular, rehabilitation, endocrine, and gastrointestinal and nutritional management. Lancet Neurol. 2018;17(3):255.)

biopsies were routinely performed to diagnose DMD. With advancements in genetic testing strategies, including multiplex ligation-dependent probe amplification, comparative genomic hybridization, Sanger sequencing, and next-generation sequencing, a molecular diagnosis can be obtained from genomic DNA so that muscle biopsies are rarely needed to diagnose DMD. If a $D M D$ gene mutation cannot be identified by using genetic testing, clinicians may choose to perform a muscle biopsy to determine the percentage of dystrophin by using histopathological staining and immunoblot analysis. If dystrophin staining is equivocal, the muscle can be sent for RNA transcription testing to identify intronic changes.

In a child with a family history of DMD, a serum CK level is recommended. In a child without a family history, the presence of global development delay, psychomotor delay, and/or motor delay prompts a serum $\mathrm{CK}$ level (CK is elevated 50-100 times normal in DMD). The liver enzymes, aspartate aminotransferase, and alanine aminotransferase are also elevated but from the muscle instead of the liver. $\gamma$-glutamyl transferase is the preferred laboratory test to check for liver disease in DMD. If CK is elevated, then DNA should 


\section{When to suspect DMD}

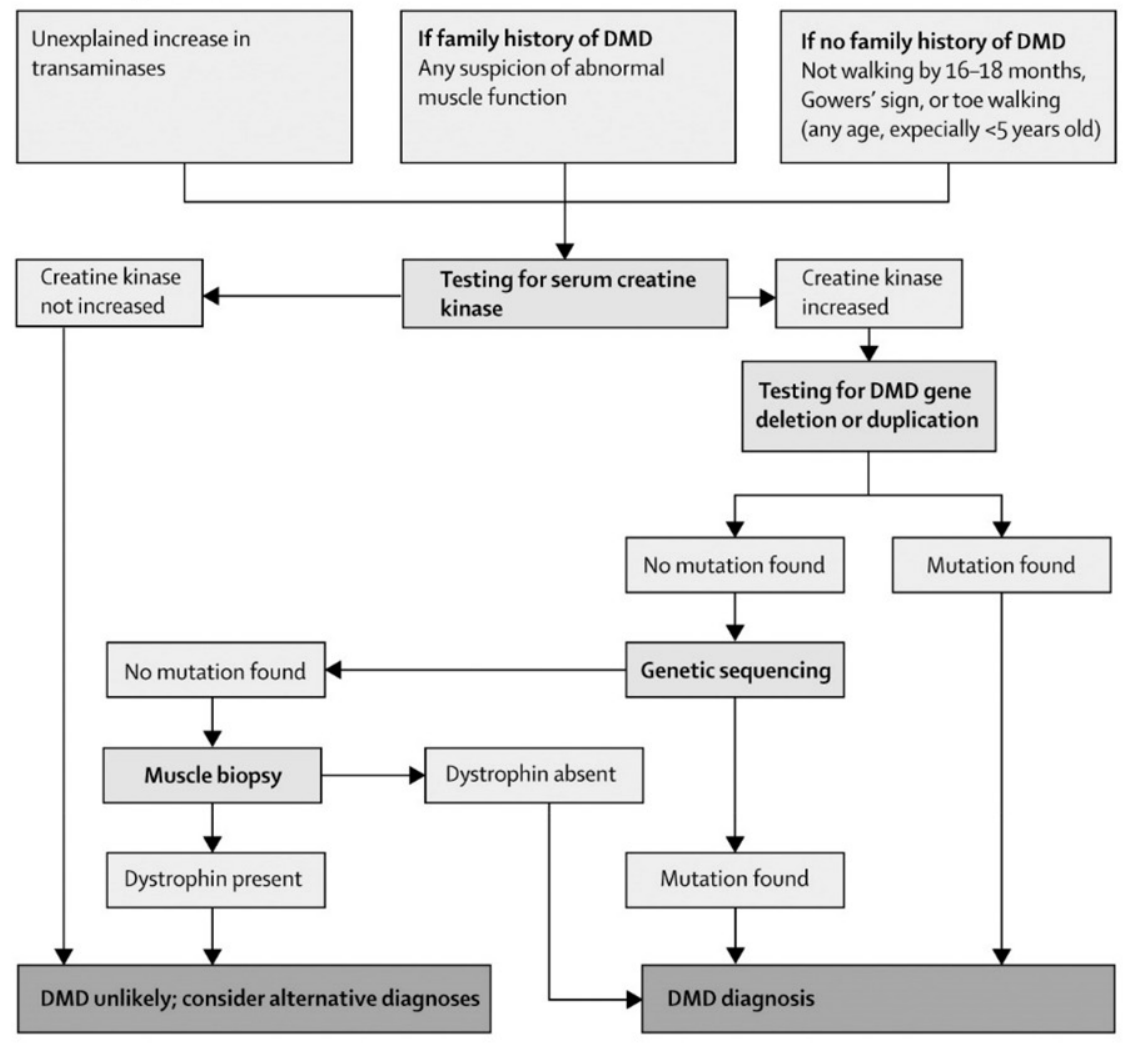

Most commonly observed early signs and symptoms in patients with DMD

\begin{tabular}{|l|}
\hline Motor \\
- Abnormal gait \\
- Calf pseudohypertrophy \\
- Inability to jump \\
- Decreased endurance \\
- Decreased head control when pulled to sit \\
- Difficulty climbing stairs \\
- Flat feet \\
- Frequent falling or clumsiness \\
- Gowers' sign on rising from floor \\
- Gross motor delay \\
- Hypotonia \\
- Inability to keep up with peers \\
- Loss of motor skills \\
- Muscle pain or cramping \\
- Toe walking \\
- Difficulty running or climbing \\
\hline
\end{tabular}

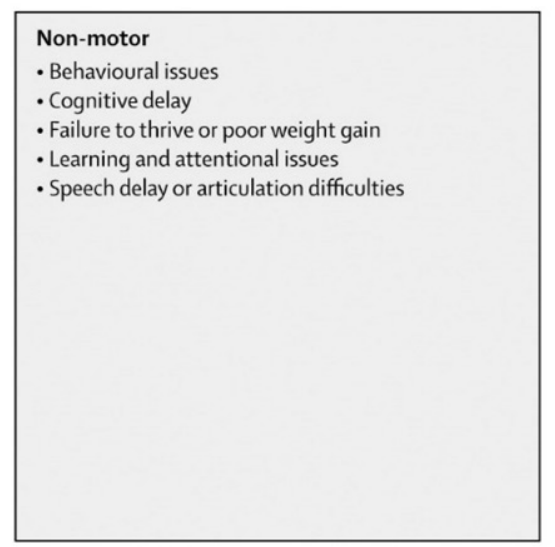

\section{FIGURE 3}

Diagnosis of Duchene muscular dystrophy. Described early signs and symptoms of DMD are based on Ciafaloni et al. ${ }^{10}$ (Reproduced with permission from Birnkrant DJ, Bushby K, Bann CM, et al. Diagnosis and management of Duchenne muscular dystrophy, part 1: diagnosis, and neuromuscular, rehabilitation, endocrine, and gastrointestinal and nutritional management. Lancet Neurol. 2018;17(3):253.)

be sent to test for exonic deletions and duplications, which are seen in $\sim 65 \%$ of cases. ${ }^{30,31}$ Table 1 includes the types of gene mutations in DMD. Multiplex ligation-dependent probe amplification is the most widely used technique and can be used to test all 79 exons. Comparative genomic hybridization is an oligoclonal-based method that can be used to detect complex rearrangements, intronic alteration, or mutation break points. ${ }^{30}$ The
TABLE 1 Types of DMD Mutation

\begin{tabular}{lc}
\hline Mutation & $\%$ \\
\hline Deletions & 65 \\
Duplications & $6-10$ \\
Point mutations & 25 \\
Complex mutations & $<2$ \\
\hline
\end{tabular}

evolution of next-generation sequencing has enabled the sequencing of millions of copies of DNA fragments simultaneously and has reduced time and cost. ${ }^{32}$

If the deletion and/or duplication test result is negative, then sequencing is conducted to identify smaller mutations. Sequencing the entire coding region can reveal small mutations, splicing mutations, or single base changes. If no mutation is identified after sequencing, a muscle biopsy can be obtained to determine the presence or absence of dystrophin by using histologic staining. The absence of dystrophin confirms a diagnosis of DMD. Reduced dystrophin could be associated with Becker muscular dystrophy or DMD depending on the presence and severity of muscle weakness on examination. Dystrophin $<3 \%$ is consistent with DMD, whereas $\geq 20 \%$ on muscle biopsy suggests that DMD is unlikely. Some variation in muscle biopsy results occurs depending on the age of the child and what part of the affected muscle was biopsied. Alternatively, tissue from the muscle can be tested through RNA transcription analysis to assess for intronic mutations that may have been identified in the other genetic strategies. Immunoblotting of the muscle biopsy also can be used. If no $D M D$ mutation is identified, the clinician can consider an alternative diagnosis, such as limb-girdle or congenital muscular dystrophy. Imaging with quantitative magnetic resonance and magnetic resonance spectroscopy reveal an increase in fat fraction with disease progression. ${ }^{33,34}$ Given the heterogeneity of affected skeletal muscle in DMD, an 


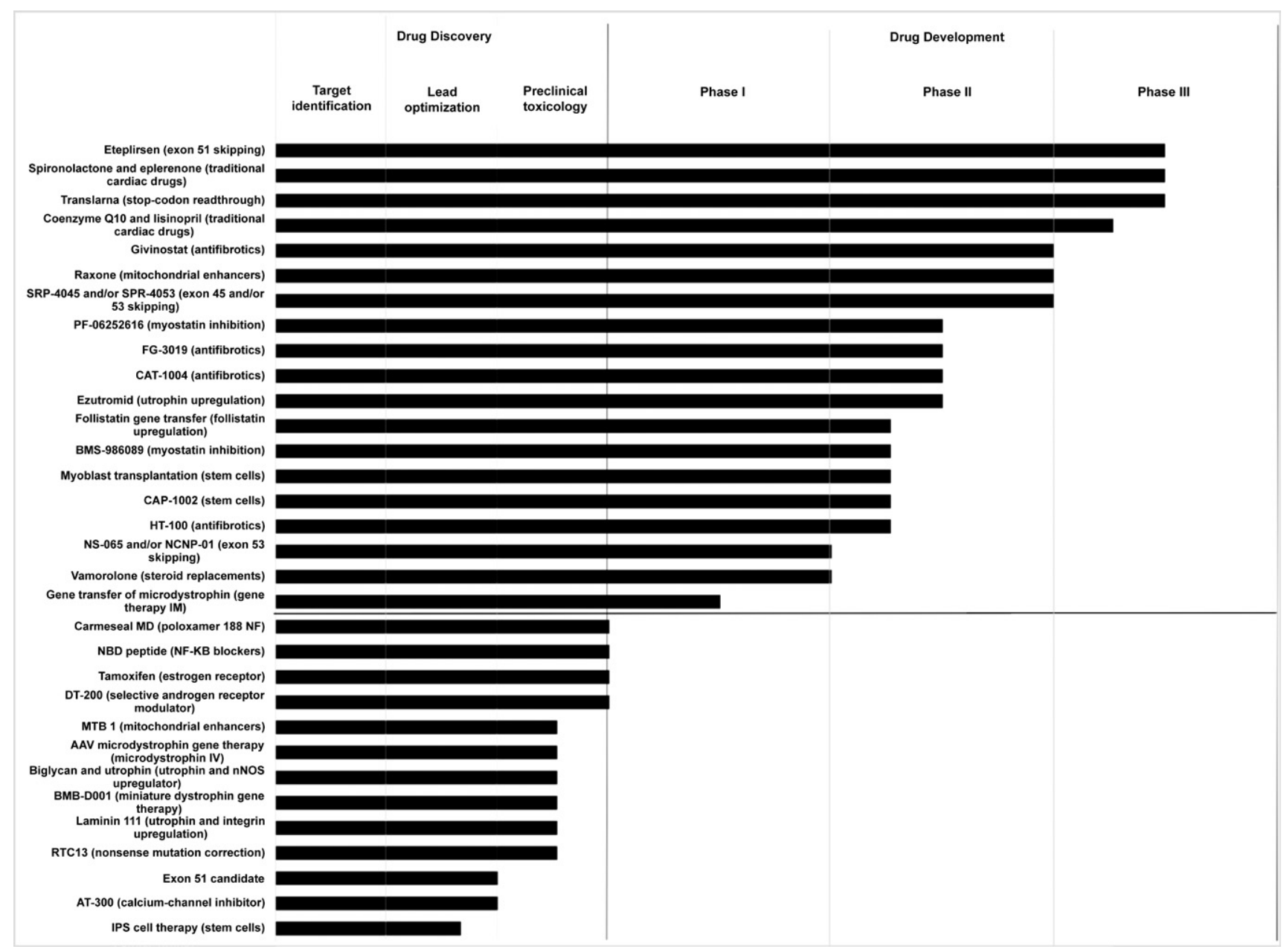

\section{FIGURE 4}

Drug discovery chart for DMD clinical trials. Illustrated is the active pace of drug discovery in DMD.

MRI-guided muscle biopsy can be applied in the diagnosis and/or confirmation of DMD when genetic testing is unrevealing.

\section{EMERGING THERAPIES}

Numerous treatment strategies have been investigated for DMD. After decades of searching for targets, identifying molecular pathways, and preclinical investigations in animal models, potential therapeutic targets have been translated to clinical trials in DMD. In this section, we review some of the main strategies and active clinical trials. Figure 4 is a chart of the potential drugs in the DMD drug discovery pipeline.

\section{Restore Protein (Dystrophin)}

Exon skipping and nonsense readthrough can restore the expression of the gene product dystrophin. These agents generate a functional or partially functional protein in DMD.

\section{Exon Skipping}

The concept behind exon skipping is targeted at the messenger RNA level and is based on the readingframe rule. The intent is to skip (or delete) an out-of-frame mutation and restore the reading frame by making an in-frame mutation that encodes a more functional protein that is consistent with the milder, Becker muscular dystrophy-like phenotype. This technology uses antisense oligonucleotides.

Two chemical constructs, 2'-0-methyl phosphorothioate and phosphorodiamidate morpholino oligomers, have been used in clinical studies to bind to exonsplice junctions and generate exon skipping. ${ }^{35,36}$ The 2'-0-methyl phosphorothioate drug, drisapersen, for exon 51 skipping, which initially showed improvement on the 6-minute walk test in early clinical trials, progressed to a larger phase III study in which it did not reach its primary end point. ${ }^{37,38}$ The phosphorodiamidate morpholino oligomers drug, eteplirsen, is also designed for exon 51 skipping. Researchers in an initial study enrolled 12 patients for $>3$ years, and these treated patients demonstrated 
a slower rate of decline in ambulation compared with untreated historical controls. ${ }^{39,40}$ Exon skippingamenable mutations constitute $\sim 80 \%$ of all DMD, of which $\sim 13 \%$ of cases are amenable to exon 51 skipping ${ }^{41}$ (Table 2). Drisapersen is administered subcutaneously, and eteplirsen is delivered by intravenous infusion. A drisapersen application to the US Food and Drug Administration (FDA) was not approved, but eteplirsen was granted accelerated approval by the FDA while an ongoing confirmatory study is underway. ${ }^{42}$

\section{Nonsense Suppression}

Nonsense mutations generate a stop codon, resulting in a truncated, nonfunctional protein. Nonsense (stop-codon) mutations comprise $\sim 10 \%$ to $15 \%$ of DMD cases. ${ }^{43,44}$ The readthrough strategy, which involves the suppression of the stop-codon mutation, encourages the ribosome to read through the stop codon, which promotes the production of dystrophin. ${ }^{45}$ Proof of concept for nonsense suppression was initially established with an aminoglycoside: gentamicin. ${ }^{46}$ Translarna (ataluren), an oral medication with a better safety profile compared with gentamicin (formerly referred to as PTC124), promotes the readthrough of premature translation termination codons. Safety and tolerability was established, and a phase IIa proofof-concept trial revealed increased dystrophin posttreatment on muscle biopsy. ${ }^{47}$ Due to the unmet need for treatments in DMD and promising early phase findings, this drug has been approved by the European Medicines Agency. ${ }^{48}$ A phase III trial revealed enrichment of effect in a subgroup of patients with a baseline 6-minute walk test between 300 and $400 \mathrm{~m}$ at enrollment. ${ }^{49}$ However, the FDA voted that the data used to support Translarna were inconclusive.
TABLE 2 Exon Skipping-Amenable Mutations

\begin{tabular}{lc}
\hline Exon Amenable to Skip & $\%$ \\
\hline 51 & 13.0 \\
45 & 8.1 \\
53 & 7.7 \\
44 & 6.2 \\
46 & 4.3 \\
52 & 4.1 \\
50 & 4.0 \\
43 & 3.8 \\
6 and 7 & 3.0 \\
8 & 2.3 \\
55 & 2.0 \\
\hline
\end{tabular}

\section{Replace Lost Dystrophin}

Utrophin is an analog of dystrophin that shares $\sim 80 \%$ sequence homology with dystrophin. ${ }^{50-52}$ SMT C1100 is a molecule that works as a utrophin modulator and is an investigational drug with the potential to replace lost dystrophin with utrophin. ${ }^{53}$ Safety and tolerability has been shown in a study of 12 patients with DMD. ${ }^{54}$ A phase II study is ongoing to evaluate the activity and safety of this orally administered drug in a larger cohort of patients.

\section{Target Signaling Pathways Anti-inflammatory Approaches}

Muscle fibers in DMD undergo inflammatory and fibrotic changes that have been responsive to glucocorticoids. As a result, antiinflammatory approaches to treat DMD remain a focus in drug discovery. Myofiber necrosis is reported to result from chronic $\mathrm{NF}-\kappa \mathrm{B}$ activation and tumor necrosis factor $\alpha .{ }^{9,55,56}$ Prednisone and deflazacort, used to treat DMD, have anti-inflammatory effects and are presumed to inhibit the $\mathrm{NF}-\kappa \mathrm{B}$ pathways. However, these drugs are generally nonspecific anti-inflammatory agents with multisystem side effects. New drugs aimed at specifically targeting NF- $\mathrm{B}$ or tumor necrosis factor $\alpha$ are being moved forward in drug discovery and are currently in the preclinical stages, poised to move to clinical trials. Vamorolone (also known as VBP15), an oral anti-inflammatory steroid with fewer side effects in preclinical and phase I trials compared with traditional glucocorticoids, has advanced to phase II in an ongoing, larger clinical trial to assess safety and efficacy.

\section{Antioxidants}

Oxidative stress can damage cellular function, specifically mitochondria. The overproduction and/or accumulation of reactive oxygen species can lead to mitochondrial dysfunction in neuromuscular disease. Studies have revealed that increased reactive oxygen species in DMD contribute to membrane permeability and protein degradation and activates inflammatory pathways, thereby exacerbating necrosis and fibrosis. Idebenone, an antioxidant that inhibits lipid peroxidation, has shown efficacy in a phase III trial, with improvement seen in respiratory function (ie, forced vital capacity). ${ }^{57}$ Idebenone is orally administered and currently undergoing regulatory review.

\section{Antifibrosis}

In DMD, endomysial fibrosis is a hallmark clinical feature associated with muscle weakness and poor long-term outcome; transforming growth factor $\beta$ (TGF- $\beta$ ) is a target in antifibrosis therapy. Therapeutic agents aimed at blocking cytokine signaling by inhibiting the TGF- $\beta$ pathway in preclinical models have been shown to decrease fibrosis in some studies, although not in others. ${ }^{58-61}$ Losartan, an antihypertensive drug with a known safety profile, was an attractive therapeutic target, but the preclinical studies that initially revealed reduced fibrosis later revealed minimal functional benefit. ${ }^{62,63}$ Another agent, oral halofuginone hydrobromide (also known as HT-100), is currently in a phase II trial to assess safety, tolerability, and dose selection for future trials. Givinostat, an oral inhibitor of histone deacetylases 
aimed at reducing fibrosis of muscle fibers and promoting muscle regeneration in $\mathrm{DMD}$, is in a phase III global clinical trial. ${ }^{64}$

\section{Phosphodiesterase 5A Inhibition}

Diminished blood flow can cause muscle damage. Mendell et al ${ }^{65,66}$ showed in the mouse model that functional ischemia produces similar changes seen in muscle fiber degeneration and regeneration in DMD. Researchers in more studies have since implicated the nitric oxide synthase pathway in ischemia and thus inhibition of phosphodiesterase (PDE) as a potential therapeutic target. ${ }^{67}$ Sildenafil, an oral PDE 5 inhibitor, was studied in adult patients with DMD and cardiomyopathy. The trial was terminated early due to worsening left-ventricular end-systolic volume in subjects on sildenafil. ${ }^{68}$ Tadalafil, another oral PDE inhibitor, was shown to restore blood supply to muscle in the mdx mouse. However, tadalafil had no effect on the primary outcome and did not lessen the decline in ambulatory ability in patients with DMD. ${ }^{69}$

\section{Myostatin Inhibition}

The inhibition of the myostatin pathway is a muscle-building therapeutic approach for muscular dystrophy. Myostatin regulates muscle growth by breaking down muscle protein, and blocking myostatin has been shown to increase muscle mass and reduce fibrosis. ${ }^{70,71}$ Wagner et al ${ }^{72}$ conducted an early phase clinical trial in adult patients with muscular dystrophy using a recombinant human antibody and showed safety, although not efficacy. New strategies and the formulation of an antimyostatin antibody, PF-06252616, have since occurred, and the agent is being used in an ongoing phase II clinical trial in patients with DMD. This agent is delivered intravenously. Similarly, an antimyostatin adnectin, BMS-0986089, is currently in phase
I or II trials in ambulatory DMD patients. This agent is delivered subcutaneously.

\section{Improve Cardiac Function}

CAP-1002 is a novel therapeutic approach in which cell therapy is used to treat cardiomyopathy in DMD. This investigational treatment is already being investigated as a treatment of postmyocardial infarction. The agent is an allogenic cell therapy derived from human heart tissue that is administered directly to the heart through the coronary arteries by cardiac catheterization. This drug is currently in the phase I or II study stage to investigate safety and tolerability.

Eplerenone, a drug that is already used in heart failure and has a known safety profile, has been investigated in a randomized, placebo-controlled clinical trial in patients with DMD and early cardiomyopathy who are already taking an angiotensinconverting enzyme inhibitor. After 12 months, it was reported that a statistically significant reduction in left-ventricular strain occurred in the treatment arm compared with a placebo. ${ }^{73}$ Although long-term benefits cannot be concluded from these findings, longitudinal data from this cohort will provide greater insight on the potential benefit of this cardiac intervention in DMD. Results after a 2-year study revealed that eplerenone can be cardioprotective in patients with DMD. ${ }^{74}$

\section{Restore Gene Function}

In a monogenetic disorder, such as DMD, the idea of replacing a defective gene with a "corrected" gene seems simple, but many challenges have been encountered to date. Strategies on how to target the desired muscle, circumvent the immune response, and achieve efficient systemic delivery are some of the major hurdles. ${ }^{75}$ The discovery of an adenoassociated virus (AAV) to be a safe and effective therapeutic tool in gene transfer has addressed some of the technical barriers. ${ }^{76,77}$ However, AAV has a limited capacity to package the entire $D M D$ gene.

\section{Gene Replacement}

In DMD, the large size of the $D M D$ gene poses the challenge of packaging into an AAV. Mini-dystrophins (ie, miniaturized versions of the $D M D$ gene) have been developed. ${ }^{78,79}$ Investigators also have packaged the gene into 2 vectors in a dual-AAV approach and showed that it restored sarcolemmal neuronal nitric oxide synthase expression in dystrophindeficient mice ${ }^{80}$ Transgene delivery by an AAV through intramuscular injection in a phase I clinical trial in humans revealed an immune response to the transgene product, bringing attention to the role of T-cell immunity to self- and nonselfdystrophin in the study design of future gene therapy trials. ${ }^{81}$ Limb vascular delivery is another method to regionally deliver the gene. ${ }^{82}$ Systemic delivery can be achieved intravenously, but targeting the gene to muscle and limiting its off-target delivery are important aspects of the gene delivery. Although gene therapy is still in early stages, the knowledge gained from the pioneering work of many dedicated investigators over several decades has taken the field closer to becoming a potential therapy. Phase I and II studies to deliver microdystrophin $\mathrm{C}$ with AAV vectors are anticipated to begin this year.

\section{Gene Editing}

A novel genetic engineering technology, clustered regularly interspaced short palindromic repeats (CRISPR) coupled with an endonuclease (CRISPR-associated protein 9), has been applied to edit mutations in the $D M D$ gene. Researchers in several laboratories have reported that gene editing can be used to improve muscle function in the mouse model and muscle stem cells. Investigators have shown 
that the editing tool was used to resect the faulty exons and partially restore protein in mice. ${ }^{83-87}$ The mice treated with CRISPR did better on functional tests compared with the untreated group but not as well as the normal mice. Although gene editing with CRISPR is closer to clinical translation now than ever before, it may be years before these technologies achieve efficiency toward clinical trials.

\section{Target Genetic Modifiers}

The vast clinical variability in DMD is well known, and environmental factors can contribute to the genetic modifier effect and heterogeneity of phenotypic features. Latent TGF- $\beta$ binding protein 4 can be used to predict the age of loss of ambulation. ${ }^{88,89}$ SPP1, a gene encoding osteopontin, acts as a pharmacodynamic biomarker of steroid response. ${ }^{89}$ These 2 pathways converge in the regulation of TGF- $\beta$. ANXA6 encodes annexin A6, a calcium-binding protein, and is correlated with sarcolemmal repair in the mouse model. ${ }^{90,91}$ These modifier genes are correlated with phenotypic variation and serve as novel therapeutic targets for future drug discovery.

\section{FUTURE DIRECTIONS}

As disease-modifying treatments emerge, patients with DMD will live longer, and they will need to be prepared to live as independently as possible. Care centers will need to incorporate health service considerations into their care plans. The molecular diagnoses stored in "unified" databases, which include molecular profiles and wellcharacterized phenotypes, can be used to augment the identification and selection of more homogeneous candidates for specific therapies as gene-derived strategies are translated to the clinics. As genetic modifiers are validated, biomarkers and novel therapeutic targets can be developed. Putative diseasemodifying strategies related to cardiac function and neuronal involvement in DMD warrant further exploration for novel targets.

\section{CONCLUSIONS}

The $D M D$ gene was identified $\sim 3$ decades ago, and the presteroid era changed after prednisone was shown to prolong ambulation. ${ }^{12}$ Glucocorticoids remain the standard of care, but significant side effects limit their therapeutic window.

As survival has improved with the launch of specialized care centers and better respiratory support, cardiac disease has become a more important cause of death. The majority of the investigational drugs improve skeletal and pulmonary function, and cardiomyopathy remains a critical area in need of effective treatment. Furthermore, addressing neurodevelopmental needs and providing early intervention are necessary. As the translational community shepherds novel therapeutics into the clinic, other initiatives are equally important, including newborn screening, management strategies for infants and toddlers, neurobehavioral management for school-aged children, transition management, and adult considerations for affected men. Newborn screening and effective treatments may ultimately extend survival in DMD beyond the third decade.

\section{ACKNOWLEDGMENT}

We thank Joan Scott (acting director, Division of Services for Children with Special Health Needs, Maternal and Child Health Bureau, Health Resources and Services Administration), who served on the Duchenne Muscular Dystrophy Care Considerations steering committee and diagnostic subcommittee.

\section{ABBREVIATIONS \\ AAV: adeno-associated virus \\ CK: creatinine kinase \\ CRISPR: clustered regularly interspaced short palindromic repeats}

DMD: Duchenne muscular dystrophy

FDA: Food and Drug Administration

PDE: phosphodiesterase

TGF- $\beta$ : transforming growth factor $\beta$

Address correspondence to Fawn Leigh, MD, Seattle Children's Hospital, University of Washington, 4800 Sandpoint Way NE, M/S MB.7.420, Seattle, WA 98105. Email: fawn.leigh@seattlechildrens.org

PEDIATRICS (ISSN Numbers: Print, 0031-4005; Online, 1098-4275).

Copyright $(92018$ by the American Academy of Pediatrics

FINANCIAL DISCLOSURE: Other than those listed under potential conflict of interest, the authors have indicated they have no financial relationships relevant to this article to disclose.

FUNDING: Supported in part by Cooperative Agreement NU380T000167, funded by the Centers for Disease Control and Prevention.

POTENTIAL CONFLICT OF INTEREST: Dr Leigh has served as a consultant to Sarepta Therapeutics and Summit Therapeutics and as principal investigator on clinical research grants sponsored by Sarepta Therapeutics, Pfizer, Atlas 5D, and Solid Biosciences; Dr Bushby has given expert advice to Solid Ventures, Gerson Lehrman Group research, Catabasis Pharmaceuticals, Bristol-Myers Squibb, PTC Therapeutics, BioMarin Pharmaceutical, and Laboratory of the Government Chemist Ltd and has received a grant and speaker fees from PTC Therapeutics; Dr Finkel has received grant support for Duchenne muscular dystrophy-related 
topics from Bristol-Myers-Squib, Catabasis Pharmaceuticals, the National Institutes of Health, Eli Lilly and Company, the Muscular Dystrophy Association, PTC Therapeutics, ReveraGen BioPharma, Santhera Pharmaceuticals, Sarepta Therapeutics, and Summit Therapeutics and has served as a paid consultant to Catabasis Pharmaceuticals, Eli Lilly and Company, PTC Therapeutics, Sarepta Therapeutics, and Summit Therapeutics, and none of these relationships are directly related to Dr Finkel's participation in this activity or article; the other authors have indicated they have no potential conflicts of interest to disclose.

\section{REFERENCES}

1. Mendell JR, Shilling C, Leslie ND, et al. Evidence-based path to newborn screening for Duchenne muscular dystrophy. Ann Neurol. 2012;71(3):304-313

2. Cowan J, Macdessi J, Stark A, Morgan G. Incidence of Duchenne muscular dystrophy in New South Wales and Australian Capital Territory. J Med Genet. 1980;17(4): 245-249

3. Romitti PA, Zhu Y, Puzhankara S, et al; MD STARnet. Prevalence of Duchenne and Becker muscular dystrophies in the United States. Pediatrics. 2015;135(3):513-521

4. Davies KE, Nowak KJ. Molecular mechanisms of muscular dystrophies: old and new players. Nat Rev Mol Cell Biol. 2006; 7(10):762-773

5. Nowak K, McCullagh K, Poon E, Davies KE. Muscular dystrophies related to the cytoskeleton/nuclear envelope. Novartis Found Symp. 2005;264:98-111; discussion 112-117, 227-230

6. Kiessling WR, Beckmann R. Serum levels of myoglobin and creatine kinase in Duchenne muscular dystrophy. Klin Wochenschr. 1981;59(7):347-348

7. Desguerre I, Mayer M, Leturcq F Barbet JP, Gherardi RK, Christov C. Endomysial fibrosis in Duchenne muscular dystrophy: a marker of poor outcome associated with macrophage alternative activation. J Neuropathol Exp Neurol. 2009;68(7):762-773

8. Klingler W, Jurkat-Rott K, LehmannHorn F, Schleip R. The role of fibrosis in Duchenne muscular dystrophy. Acta Myol. 2012;31 (3):184-195

9. Wynn TA. Cellular and molecular mechanisms of fibrosis. J Pathol. 2008;214(2):199-210

10. Ciafaloni E, Fox DJ, Pandya S, et al. Delayed diagnosis in Duchenne muscular dystrophy: data from the Muscular Dystrophy Surveillance, Tracking, and Research Network
(MD STARnet). J Pediatr. 2009;155(3): 380-385

11. Eagle M, Baudouin SV, Chandler C, Giddings DR, Bullock R, Bushby K. Survival in Duchenne muscular dystrophy: improvements in life expectancy since 1967 and the impact of home nocturnal ventilation. Neuromuscul Disord. 2002;12(10):926-929

12. Mendell JR, Moxley RT, Griggs RC, et al. Randomized, double-blind six-month trial of prednisone in Duchenne's muscular dystrophy. N Engl J Med. 1989;320(24):1592-1597

13. Matthews E, Brassington R, Kuntzer T, Jichi F, Manzur AY. Corticosteroids for the treatment of Duchenne muscular dystrophy. Cochrane Database Syst Rev. 2016;(5):CD003725

14. Griggs RC, Herr BE, Reha A, et al. Corticosteroids in Duchenne muscular dystrophy: major variations in practice. Muscle Nerve. 2013;48(1):27-31

15. Birnkrant DJ, Ararat E, Mhanna MJ. Cardiac phenotype determines survival in Duchenne muscular dystrophy. Pediatr Pulmonol. 2016;51(1):70-76

16. Buddhe S, Cripe L, Friedland-Little $J$, et al. Cardiac management of the patient with Duchenne muscular dystrophy. Pediatrics. 2018;142(suppl 2):e20180333|

17. Birnkrant DJ, Bushby K, Bann CM, et al: DMD Care Considerations Working Group. Diagnosis and management of Duchenne muscular dystrophy, part 2: respiratory, cardiac, bone health, and orthopaedic management. Lancet Neurol. 2018;17(4):347-361

18. Webster C, Silberstein L, Hays AP, Blau HM. Fast muscle fibers are preferentially affected in Duchenne muscular dystrophy. Cell. 1988;52(4):503-513

19. Cea LA, Puebla C, Cisterna BA, et al. Fast skeletal myofibers of $\mathrm{mdx}$ mouse, model of Duchenne muscular dystrophy, express connexin hemichannels that lead to apoptosis. Cell Mol Life Sci. 2016;73(13):2583-2599

20. Bayley N. Bayley Scales of Infant and Toddler Development: Administration Manual. San Antonio, TX: Harcourt Assessment; 2006

21. Connolly AM, Florence JM, Cradock MM, et al; MDA DMD Clinical Research Network. One year outcome of boys with Duchenne muscular dystrophy using the Bayley-III scales of infant and toddler development. Pediatr Neurol. 2014;50(6):557-563

22. Albers CA, Grieve AJ. Test review: Bayley, N. (2006). Bayley scales of infant and toddler development-third edition. San Antonio, TX: Harcourt Assessment. J Psychoeduc Assess. 2007;25(2):180-190

23. Fenichel GM, Florence JM, Pestronk A, et al. Long-term benefit from prednisone therapy in Duchenne muscular dystrophy. Neurology. 1991;41(12):1874-1877

24. Griggs RC, Moxley RT III, Mendell JR, et al; Clinical Investigation of Duchenne Dystrophy Group. Prednisone in Duchenne dystrophy. A randomized, controlled trial defining the time course and dose response. Arch Neurol. 1991;48(4):383-388

25. Manzur AY, Kuntzer T, Pike M, Swan A. Glucocorticoid corticosteroids for Duchenne muscular dystrophy. Cochrane Database Syst Rev. 2008;(1):CD003725

26. Biggar WD, Harris VA, Eliasoph L, Alman B. Long-term benefits of deflazacort treatment for boys with Duchenne muscular dystrophy in their second decade. Neuromuscul Disord. 2006;16(4):249-255

27. Mavrogeni S, Papavasiliou A, Douskou M, Kolovou G, Papadopoulou E, Cokkinos DV. Effect of deflazacort on cardiac and sternocleidomastoid muscles in Duchenne muscular dystrophy: a magnetic resonance 
imaging study. Eur J Paediatr Neurol. 2009;13(1):34-40

28. Koenig M, Beggs AH, Moyer M, et al. The molecular basis for Duchenne versus Becker muscular dystrophy: correlation of severity with type of deletion. Am J Hum Genet. 1989;45(4):498-506

29. Monaco AP, Bertelson CJ, Liechti-Gallati $\mathrm{S}$, Moser H, Kunkel LM. An explanation for the phenotypic differences between patients bearing partial deletions of the DMD locus. Genomics. 1988;2(1):90-95

30. Abbs S, Tuffery-Giraud S, Bakker E, Ferlini A, Sejersen T, Mueller CR. Best practice guidelines on molecular diagnostics in Duchenne/Becker muscular dystrophies. Neuromuscul Disord. 2010;20(6):422-427

31. Cunniff C, Andrews J, Meaney FJ, et al. Mutation analysis in a population-based cohort of boys with Duchenne or Becker muscular dystrophy. J Child Neurol. 2009;24(4):425-430

32. Ashton EJ, Yau SC, Deans ZC, Abbs SJ. Simultaneous mutation scanning for gross deletions, duplications and point mutations in the DMD gene. Eur J Hum Genet. 2008;16(1):53-61

33. Willcocks RJ, Arpan IA, Forbes SC, et al. Longitudinal measurements of MRIT2 in boys with Duchenne muscular dystrophy: effects of age and disease progression. Neuromuscul Disord. 2014;24(5):393-401

34. Willcocks RJ, Rooney WD, Triplett WT, et al. Multicenter prospective longitudinal study of magnetic resonance biomarkers in a large Duchenne muscular dystrophy cohort. Ann Neurol. 2016;79(4):535-547

35. Aartsma-Rus A, van 0mmen GJ. Antisense-mediated exon skipping: a versatile tool with therapeutic and research applications. RNA. 2007;13(10):1609-1624

36. Aartsma-Rus A. Overview on AON design. Methods Mol Biol. 2012;867:117-129

37. Voit T, Topaloglu H, Straub V, et al. Safety and efficacy of drisapersen for the treatment of Duchenne muscular dystrophy (DEMAND II): an exploratory, randomised, placebo-controlled phase 2 study. Lancet Neurol. 2014;13(10):987-996

38. Flanigan KM, Voit T, Rosales XQ, et al. Pharmacokinetics and safety of single doses of drisapersen in non-ambulant subjects with Duchenne muscular dystrophy: results of a double-blind randomized clinical trial. Neuromuscul Disord. 2014;24(1):16-24

39. Mendell JR, Goemans N, Lowes LP, et al; Eteplirsen Study Group and Telethon Foundation DMD Italian Network. Longitudinal effect of eteplirsen versus historical control on ambulation in Duchenne muscular dystrophy. Ann Neurol. 2016;79(2):257-271

40. Mendell JR, Rodino-Klapac LR, Sahenk Z, et al; Eteplirsen Study Group. Eteplirsen for the treatment of Duchenne muscular dystrophy. Ann Neurol. 2013;74(5):637-647

41. Aartsma-Rus A, Fokkema I, Verschuuren J, et al. Theoretic applicability of antisense-mediated exon skipping for Duchenne muscular dystrophy mutations. Hum Mutat. 2009;30(3):293-299

42. Food and Drug Administration. FDA news release: FDA grants accelerated approval to first drug for Duchenne muscular dystrophy. 2016. Available at: https://www.fda.gov/NewsEvents/ Newsroom/PressAnnouncements/ ucm521263.htm. Accessed November 8, 2017

43. Bladen CL, Salgado D, Monges S, et al. The TREAT-NMD DMD global database: analysis of more than 7,000 Duchenne muscular dystrophy mutations. Hum Mutat. 2015;36(4):395-402

44. Mendell JR, Buzin CH, Feng J, et al. Diagnosis of Duchenne dystrophy by enhanced detection of small mutations. Neurology. 2001;57 (4):645-650

45. Finkel RS. Read-through strategies for suppression of nonsense mutations in Duchenne/ Becker muscular dystrophy: aminoglycosides and ataluren (PTC124). J Child Neurol. 2010;25(9):1158-1164

46. Malik V, Rodino-Klapac LR, Viollet L, Mendell JR. Aminoglycoside-induced mutation suppression (stop codon readthrough) as a therapeutic strategy for Duchenne muscular dystrophy. Ther Adv Neurol Disorder. 2010;3(6):379-389

47. Hirawat S, Welch EM, Elfring GL, et al. Safety, tolerability, and pharmacokinetics of PTC124, a nonaminoglycoside nonsense mutation suppressor, following single- and multiple-dose administration to healthy male and female adult volunteers. J Clin Pharmacol. 2007;47 (4):430-444

48. Mullard A. EMA reconsiders 'readthrough' drug against Duchenne muscular dystrophy following appeal. Nat Biotechnol. 2014;32 (8):706

49. McDonald CM, Campbell C, Torricelli RE, et al; Clinical Evaluator Training Group; ACT DMD Study Group. Ataluren in patients with nonsense mutation Duchenne muscular dystrophy (ACT DMD): a multicentre, randomised, double-blind, placebocontrolled, phase 3 trial. Lancet. 2017;390(10101):1489-1498

50. Love DR, Byth BC, Tinsley JM, Blake DJ, Davies KE. Dystrophin and dystrophin related proteins: a review of protein and RNA studies. Neuromuscul Disord. 1993;3(1):5-21

51. Tinsley JM, Blake DJ, Roche A, et al. Primary structure of dystrophin-related protein. Nature. 1992;360 (6404):591-593

52. Tinsley JM, Blake DJ, Pearce M, Knight AE, Kendrick-Jones J, Davies KE. Dystrophin and related proteins. Curr Opin Genet Dev. 1993;3(3):484-490

53. Tinsley JM, Davies KE. Utrophin: a potential replacement for dystrophin? Neuromuscul Disord. 1993;3(5-6):537-539

54. De Moor 0, Dorgan CR, Johnson $P D$, et al. Discovery and SAR of 2-arylbenzotriazoles and 2-arylindazoles as potential treatments for Duchenne muscular dystrophy. Bioorg Med Chem Lett. 2011;21(16):4828-4831

55. Acharyya S, Villalta SA, Bakkar N, et al. Interplay of IKK/NF-kappaB signaling in macrophages and myofibers promotes muscle degeneration in Duchenne muscular dystrophy. J Clin Invest. 2007;117(4):889-901

56. Wynn TA, Barron L, Thompson RW, et al. Quantitative assessment of 
macrophage functions in repair and fibrosis. Curr Protoc Immunol. 2011;Chapter 14:Unit14.22

57. Buyse GM, Voit T, Schara U, et al; DELOS Study Group. Efficacy of idebenone on respiratory function in patients with Duchenne muscular dystrophy not using glucocorticoids (DELOS): a double-blind randomised placebo-controlled phase 3 trial. Lancet. 2015;385(9979):1748-1757

58. Welch RD, Billon C, Valfort AC, Burris TP, Flaveny CA. Pharmacological inhibition of REV-ERB stimulates differentiation, inhibits turnover and reduces fibrosis in dystrophic muscle. Sci Rep. 2017;7(1):17142

59. Acuña MJ, Salas D, Córdova-Casanova A, et al. Blockade of Bradykinin receptors worsens the dystrophic phenotype of $\mathrm{mdx}$ mice: differential effects for B1 and B2 receptors. $\checkmark$ Cell Commun Signal. 2018;12(3): 589-601

60. Andreetta F, Bernasconi P, Baggi F, et al. Immunomodulation of TGF-beta 1 in mdx mouse inhibits connective tissue proliferation in diaphragm but increases inflammatory response: implications for antifibrotic therapy. J Neuroimmunol. 2006;175(1-2):77-86

61. Morales MG, Cabrera D, Céspedes C, et al. Inhibition of the angiotensinconverting enzyme decreases skeletal muscle fibrosis in dystrophic mice by a diminution in the expression and activity of connective tissue growth factor (CTGF/CCN-2). Cell Tissue Res. 2013;353(1):173-187

62. Bish LT, Yarchoan M, Sleeper MM, et al. Chronic losartan administration reduces mortality and preserves cardiac but not skeletal muscle function in dystrophic mice. PLoS One. 2011;6(6):e20856

63. Spurney CF, Sali A, Guerron AD, et al. Losartan decreases cardiac muscle fibrosis and improves cardiac function in dystrophin-deficient $\mathrm{mdx}$ mice. J Cardiovasc Pharmacol Ther. 2011;16(1):87-95

64. Bettica P, Petrini S, D’Oria V, et al. Histological effects of givinostat in boys with Duchenne muscular dystrophy. Neuromuscul Disord. 2016;26(10):643-649
65. Mendell JR, Engel WK, Derrer EC Duchenne muscular dystrophy: functional ischemia reproduces its characteristic lesions. Science. 1971;172(3988):1143-1145

66. Mendell JR, Engel WK, Derrer EC. Increased plasma enzyme concentrations in rats with functional ischaemia of muscle provide a possible model of Duchenne muscular dystrophy. Nature. 1972;239(5374):522-524

67. Asai A, Sahani N, Kaneki M, Ouchi Y, Martyn JA, Yasuhara SE. Primary role of functional ischemia, quantitative evidence for the two-hit mechanism, and phosphodiesterase- 5 inhibitor therapy in mouse muscular dystrophy. PLoS One. 2007;2(8):e806

68. Leung DG, Herzka DA, Thompson WR, et al. Sildenafil does not improve cardiomyopathy in Duchenne/Becker muscular dystrophy. Ann Neurol. 2014;76(4):541-549

69. Victor RG, Sweeney HL, Finkel R, et al; Tadalafil DMD Study Group. A phase 3 randomized placebo-controlled trial of tadalafil for Duchenne muscular dystrophy. Neurology. 2017;89(17):1811-1820

70. McPherron AC, Lawler AM, Lee SJ. Regulation of skeletal muscle mass in mice by a new TGF-beta superfamily member. Nature. 1997;387 (6628):83-90

71. Wagner KR, McPherron AC, Winik N, Lee SJ. Loss of myostatin attenuates severity of muscular dystrophy in $\mathrm{mdx}$ mice. Ann Neurol. 2002;52(6):832-836

72. Wagner KR, Fleckenstein JL, Amato AA, et al. A phase I/II trial of MY0-029 in adult subjects with muscular dystrophy. Ann Neurol. 2008;63(5):561-571

73. Raman SV, Hor KN, Mazur W, et al. Eplerenone for early cardiomyopathy in Duchenne muscular dystrophy: a randomised, double-blind, placebocontrolled trial. Lancet Neurol. 2015;14(2):153-161

74. Raman SV, Hor KN, Mazur W, et al. Eplerenone for early cardiomyopathy in Duchenne muscular dystrophy: results of a two-year open-label extension trial. Orphanet J Rare Dis. 2017;12(1):39
75. Mendell JR, Rodino-Klapac L, Sahenk Z, et al. Gene therapy for muscular dystrophy: lessons learned and path forward. Neurosci Lett. 2012;527 (2):90-99

76. Asokan A, Schaffer DV, Samulski RJ. The AAV vector toolkit: poised at the clinical crossroads. Mol Ther. 2012;20(4):699-708

77. Mingozzi F, High KA. Therapeutic in vivo gene transfer for genetic disease using AAV: progress and challenges. Nat Rev Genet. 2011;12(5):341-355

78. Decrouy A, Renaud JM, Davis HL, Lunde JA, Dickson G, Jasmin BJ. Minidystrophin gene transfer in $\mathrm{mdx} 4 \mathrm{cv}$ diaphragm muscle fibers increases sarcolemmal stability. Gene Ther. 1997;4(5):401-408

79. Li S, Kimura E, Ng R, et al. A highly functional mini-dystrophin/GFP fusion gene for cell and gene therapy studies of Duchenne muscular dystrophy. Hum Mol Genet. 2006;15(10):1610-1622

80. Zhang Y, Yue Y, Li L, et al. Dual AAV therapy ameliorates exercise-induced muscle injury and functional ischemia in murine models of Duchenne muscular dystrophy. Hum Mol Genet. 2013;22(18):3720-3729

81. Mendell JR, Campbell K, Rodino-Klapac $L$, et al. Dystrophin immunity in Duchenne's muscular dystrophy. N Engl J Med. 2010;363(15):1429-1437

82. Rodino-Klapac LR, Janssen PM, Montgomery CL, et al. A translational approach for limb vascular delivery of the micro-dystrophin gene without high volume or high pressure for treatment of Duchenne muscular dystrophy. J Trans/ Med. 2007;5:45

83. Bengtsson NE, Hall JK, Odom GL, et al. Muscle-specific CRISPR/Cas9 dystrophin gene editing ameliorates pathophysiology in a mouse model for Duchenne muscular dystrophy. Nat Commun. 2017;8:14454

84. Nelson CE, Hakim CH, Ousterout DG, et al. In vivo genome editing improves muscle function in a mouse model of Duchenne muscular dystrophy. Science. 2016;351(6271):403-407

85. Tabebordbar M, Zhu K, Cheng JKW, et al. In vivo gene editing in dystrophic mouse muscle and muscle stem cells. Science. 2016;351(6271):407-411 
86. Long C, McAnally JR, Shelton JM, Mireault AA, Bassel-Duby R, Olson EN. Prevention of muscular dystrophy in mice by CRISPR/Cas9-mediated editing of germline DNA. Science. 2014;345(6201):1184-1188

87. Long C, Amoasii L, Mireault AA, et al. Postnatal genome editing partially restores dystrophin expression in a mouse model of muscular dystrophy. Science. 2016;351(6271):400-403
88. Flanigan KM, Ceco E, Lamar KM, et al; United Dystrophinopathy Project. LTBP4 genotype predicts age of ambulatory Ioss in Duchenne muscular dystrophy. Ann Neurol. 2013;73(4):481-488

89. Bello L, Kesari A, Gordish-Dressman $\mathrm{H}$, et al; Cooperative International Neuromuscular Research Group Investigators. Genetic modifiers of ambulation in the Cooperative International Neuromuscular Research
Group Duchenne Natural History Study. Ann Neurol. 2015;77(4):684-696

90. Swaggart KA, Demonbreun AR, Vo AH, et al. Annexin A6 modifies muscular dystrophy by mediating sarcolemmal repair. Proc Natl Acad Sci USA. 2014;111(16):6004-6009

91. Swaggart KA, McNally EM. Modifiers of heart and muscle function: where genetics meets physiology. Exp Physiol. 2014;99(4):621-626 
Neurology Care, Diagnostics, and Emerging Therapies of the Patient With Duchenne Muscular Dystrophy

Fawn Leigh, Alessandra Ferlini, Doug Biggar, Katharine Bushby, Richard Finkel, Lauren P. Morgenroth and Kathryn R. Wagner

Pediatrics 2018;142;S5

DOI: $10.1542 /$ peds.2018-0333C

\section{Updated Information \&} Services

References

Permissions \& Licensing

Reprints including high resolution figures, can be found at:

http://pediatrics.aappublications.org/content/142/Supplement_2/S5

This article cites 89 articles, 11 of which you can access for free at: http://pediatrics.aappublications.org/content/142/Supplement_2/S5\# BIBL

Information about reproducing this article in parts (figures, tables) or in its entirety can be found online at:

http://www.aappublications.org/site/misc/Permissions.xhtml

Information about ordering reprints can be found online:

http://www.aappublications.org/site/misc/reprints.xhtml

\section{American Academy of Pediatrics}

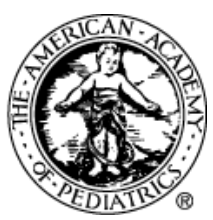




\title{
PED I ATR I C S
}

OFFICIAL JOURNAL OF THE AMERICAN ACADEMY OF PEDIATRICS

\author{
Neurology Care, Diagnostics, and Emerging Therapies of the Patient With \\ Duchenne Muscular Dystrophy \\ Fawn Leigh, Alessandra Ferlini, Doug Biggar, Katharine Bushby, Richard Finkel, \\ Lauren P. Morgenroth and Kathryn R. Wagner \\ Pediatrics 2018;142;S5 \\ DOI: $10.1542 /$ peds.2018-0333C
}

The online version of this article, along with updated information and services, is located on the World Wide Web at:

http://pediatrics.aappublications.org/content/142/Supplement_2/S5

Data Supplement at:

http://pediatrics.aappublications.org/content/suppl/2018/09/23/peds.2018-0333C.DCSupplemental

Pediatrics is the official journal of the American Academy of Pediatrics. A monthly publication, it has been published continuously since 1948. Pediatrics is owned, published, and trademarked by the American Academy of Pediatrics, 345 Park Avenue, Itasca, Illinois, 60143. Copyright (C) 2018 by the American Academy of Pediatrics. All rights reserved. Print ISSN: 1073-0397.

\section{American Academy of Pediatrics}

DEDICATED TO THE HEALTH OF ALL CHILDREN ${ }^{\circledR}$ 